\title{
Ruthenium-Catalyzed Direct Cross-Coupling of Secondary Alcohols to $\beta$-Disubstituted Ketones
}

\author{
Subramanian Thiyagarajan \\ Chidambaram Gunanathan* (ic) \\ School of Chemical Sciences, National Institute of Science Edu- \\ cation and Research (NISER), HBNI, Bhubaneswar-752050, India \\ gunanathan@niser.ac.in
}

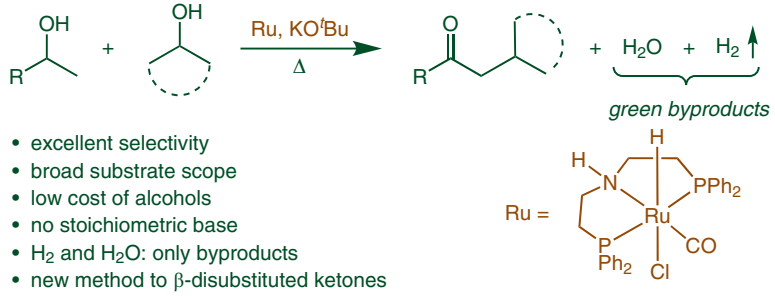

- new method to $\beta$-disubstituted ketones

\begin{abstract}
Received: 17.06.2019
Accepted after revision: 01.08.2019

Published online: 13.08 .2019

DOI: 10.1055/s-0037-1611912; Art ID: st-2019-p0313-sp

Abstract The $\beta$-disubstituted ketone functionality is prevalent in biologically active compounds and in pharmaceuticals. A ruthenium-catalyzed direct synthesis of $\beta$-disubstituted ketones by cross-coupling of two different secondary alcohols is reported. This new protocol was applied to the synthesis of variety of $\beta$-disubstituted ketones from various cyclic, acyclic, symmetrical, and unsymmetrical secondary alcohols. An amine-amide metal-ligand cooperation in a Ru catalyst facilitates the activation and formation of covalent bonds in selective sequences to provide the products. Kinetic and deuterium-labeling experiments suggested that aliphatic alcohols oxidize faster than benzylic secondary alcohols. A plausible mechanism is proposed on the basis of mechanistic and kinetic studies. Water and $\mathrm{H}_{2}$ are the only byproducts from this selective cross-coupling of secondary alcohols.

1 Introduction

2 Catalytic Self- or Cross-Coupling of Alcohols and Selectivity Challenges

3 Recent Developments in the Synthesis of $\beta$-Disubstituted Ketones

4 Scope of Ruthenium-Catalyzed Cross-Couplings of Secondary Alcohols

$5 \quad$ Mechanistic Studies and Proposed Mechanism

6 Conclusion
\end{abstract}

Key words cross-coupling, alcohols, ketones, ruthenium catalysis, homogeneous catalysis, green synthesis

\section{Introduction}

Ketones are important compounds that are widely used as solvents in the chemical industry and also serve as basic building blocks in syntheses of many natural products. ${ }^{1}$ In particular, $\alpha$ - and $\beta$-substituted ketones are structural motifs present in many natural products and bioactive compounds. These $\alpha$ - and $\beta$-substituted ketones are usually synthesized by the reaction of an alkyl halide with a ketone in the presence of a strong base such as BuLi or LDA. ${ }^{2}$ Such conventional alkylation methods suffer from various disadvantages, such as the use of toxic alkyl halides, the need for cryogenic conditions, or the production of stoichiometric amounts of metal salts as chemical waste, thereby decreasing the atom economy of the alkylation reactions. Because of the versatile utility of ketones, the development of new methods for their synthesis has received much attention. As a result, atom-economical, practical, environmentally friendly, and efficient catalytic methods have been devised to produce $\alpha$ - and $\beta$-substituted ketones. Sustainable development from renewable raw materials is one of the contemporary challenges for organic synthesis. ${ }^{3}$ Alcohols are good choices as alkylating partners for alkylation reactions because they are abundant in nature, biorenewable, cheap, and easy to handle and store. ${ }^{4}$

In recent years, the borrowing-hydrogen methodology (or hydrogen autotransfer process) has gained importance for the construction of $\mathrm{C}-\mathrm{C}$ and $\mathrm{C}-\mathrm{N}$ bonds by using alcohols (Scheme 1). ${ }^{4,5}$ Notably, $\mathrm{H}_{2} \mathrm{O}$ is the only byproduct from

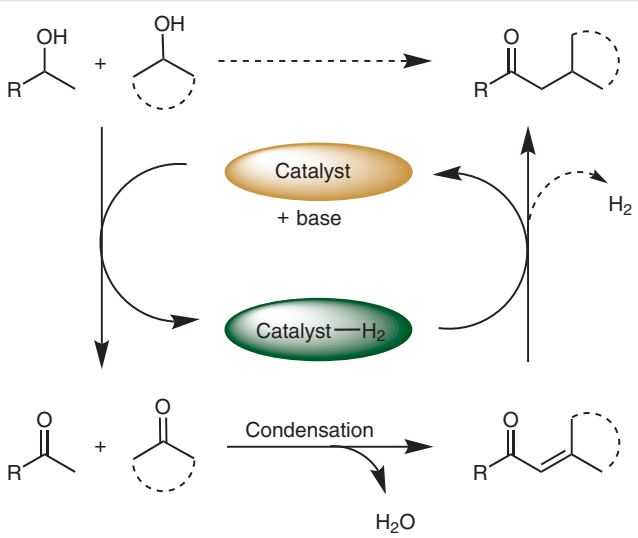

Scheme 1 Borrowing-hydrogen methodology in cross-coupling of secondary alcohols 


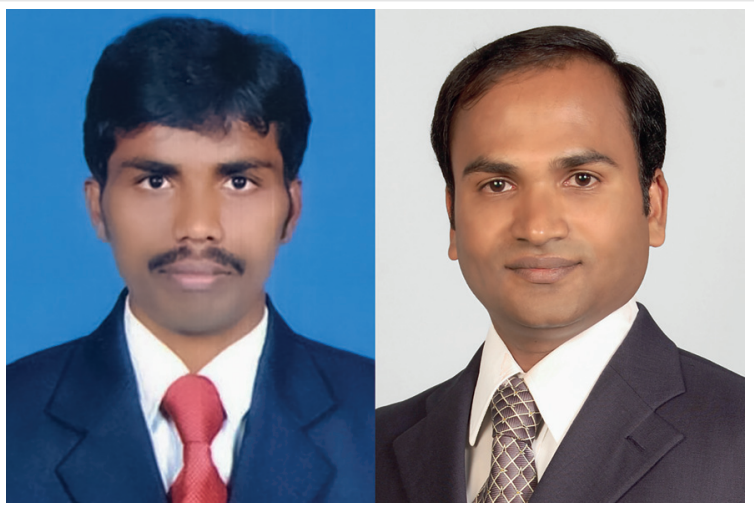

Subramanian Thiyagarajan (left) was born in Karur, Tamilnadu, India. He received his B.Sc. in 2012 and his M.Sc. in 2014 from the St. Joseph's College (Bharathidasan University), Tiruchirappalli. In 2015 he joined the research group of Dr. C. Gunanathan as a junior research fellow for his doctoral studies in the School of Chemical Sciences, National Institute of Science Education and Research (NISER), Bhubaneswar, India. His current researches focus on syntheses and green catalytic transformations in the presence of ruthenium pincer complexes. Chidambaram Gunanathan (right) was born in Kothamangalam, Tamilnadu, India. He completed his B.Sc. in chemistry at RKM Vivekananda College (1997), and his M.Sc. in organic chemistry at the Department of Organic Chemistry, University of Madras, Chennai (1999). He obtained his Ph.D. in chemistry from the Central Salt and Marine Chemicals Research Institute (CSMCRI, 2005), where he worked in the group of Professor S. Muthusamy. For a postdoctoral stint, he joined the groups of Professors David Milstein and Hadassa Degani at the Weizmann Institute of Science, Israel, where he was also a Dean of Faculty Postdoctoral Fellow. He then spent two years as an Alexander von Humboldt Research Fellow in the group of Professor Walter Leitner at RWTH Aachen University, Germany. In 2011, he joined NISER, Bhubaneswar, as an assistant professor. He is a recipient of a Ramanujan Fellowship from DST-SERB, New Delhi. He was promoted to reader in 2013 and to associate professor in 2017. His research interests include the catalytic applications of pincer complexes for sustainable development and the development of atom-economical hydroelementation processes.

this method. An alternative approach for the formation of new $\mathrm{C}-\mathrm{C}$ and $\mathrm{C}-\mathrm{N}$ bonds through acceptorless dehydrogenation of alcohols has also been developed. ${ }^{6}$ Remarkably, these processes are green and sustainable as they do not use hydrogen acceptors or oxidants, and they liberate hydrogen and water as the only byproducts.

\section{Catalytic Self- or Cross-Coupling of Alco- hols and Selectivity Challenges}

By using borrowing-hydrogen or acceptorless-dehydrogenation concepts, environmentally benign synthetic methodologies have been developed. Catalytic self-couplings and cross-couplings of primary alcohols to provide esters have been reported. ${ }^{7,8}$ Catalytic dimerization of primary alcohols to give $\beta$-alkylated alcohols have also been reported in the literature. ${ }^{9}$ Self-couplings of secondary alcohols to provide ketones have been developed (Scheme 2a). ${ }^{10}$
Recently, cross-couplings of secondary alcohols with primary alcohols to provide substituted ketones or alcohols have also been reported (Scheme 2b)., ${ }^{8,11}$

a) Catalytic self-coupling of alcohols

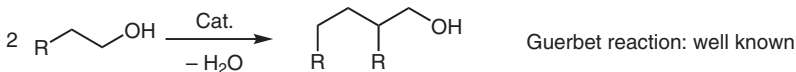

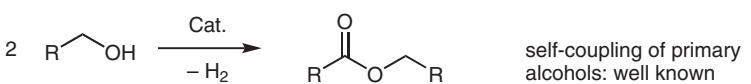

$$
\begin{aligned}
& 2 \stackrel{\text { Cat. }}{\underset{-\mathrm{H}_{2},-\mathrm{H}_{2} \mathrm{O}}{\mathrm{OH}}}
\end{aligned}
$$

b) Catalytic cross-coupling of alcohols

$$
\text { (cat) }
$$

Scheme 2 Catalytic self-couplings and cross-couplings of alcohols. (Reprinted with permission from reference 12. @ 2019, American Chemical Society.)

Unlike other coupling reactions of alcohols, the catalytic cross-coupling of secondary alcohols was unknown until our recent report (Scheme 3a). ${ }^{12}$ Cross-coupling of secondary alcohols is a reaction in which two different secondary alcohols react together with the help of a metal catalyst to form a new covalent bond. In general, the major challenge

a) Direct cross-coupling of secondary alcohols to $\beta$-disubstituted ketones

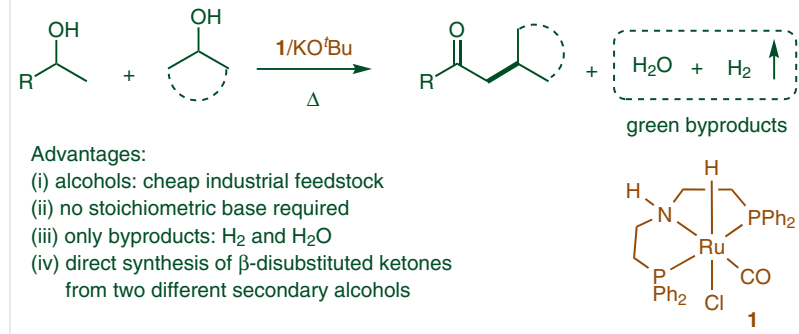

b) Selectivity challenges: direct cross-coupling of secondary alcohols

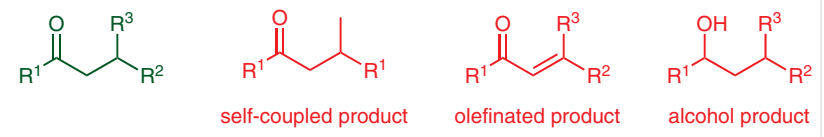

desired product highly challenging

competing byproducts

Scheme 3 Ruthenium-catalyzed direct cross-coupling of secondary alcohols and selectivity challenges. (Reprinted with permission from reference 12. @ 2019, American Chemical Society) 
in cross-coupling of secondary alcohols is to minimize the self-coupling of ketones generated in situ from both secondary alcohols. In addition, under basic conditions ketones can provide undesired aldol side reactions (Scheme $3 \mathrm{~b})$. Controlling the $\mathrm{C}-\mathrm{C}$ coupling of secondary alcohols to give $\beta$-disubstituted ketones exclusively is highly challenging. Thus, catalytic methods have been developed to synthesize $\beta$-disubstituted ketones.

\section{Recent Developments in the Synthesis of $\beta$-Disubstituted Ketones}

A few methods have recently been reported for the synthesis of $\beta$-disubstituted ketones (Scheme 4). In 2015, Sun and co-workers reported a peroxide-promoted decarboxylative alkylation of cinnamic acids with alkenes to provide $\beta$-disubstituted ketones. ${ }^{13}$ More recently, an iron-catalyzed oxyalkylation of alkynes with peroxides to provide various $\beta$-disubstituted ketones was demonstrated. ${ }^{14}$ Reaction of chloro ketones with a Grignard reagents in the presence of zinc chloride and copper acetate gave ketones in good yields. ${ }^{15}$ Moreover, a iridium-catalyzed photoredox oxyalkylation of styrene derivatives and a decarboxylative alkylation of silyl enol ethers have been developed to provide a variety of $\beta$-disubstituted ketones. ${ }^{16}$ These reported methods all suffer from various serious drawbacks, such as the use of excess amounts of acids or peroxides as additives that produce copious amounts of waste; the use of Grignard reagents and chloro ketones, which produce hazardous organometallic waste; or the use of use of prefunctionalized $\mathrm{N}$-(acyloxy)phthalimides as alkylating partners. Moreover, all these reactions necessitate the use of expensive chemicals, excess amounts of oxidants or metallic halides, or prefunctionalized starting materials, which are undesired as they do not provide environmentally benign processes. Thus, it was important to develop a practical catalytic protocol that does not require stoichiometric additives or prefunctionalization and that can proceed without producing hazardous chemical waste.

Catalytic dehydrogenative coupling of alcohols has been recognized as an alternative protocol for the synthesis of substituted ketones. Recently, Donohoe and co-workers reported an alkylation of ketones by using secondary alcohols to provide $\beta$-disubstituted ketones through a borrowinghydrogen methodology. ${ }^{17}$ However, this alkylation protocol requires excess amounts of base, and its substrate scope is limited to bulky ketones [e.g., 1-(pentamethylphenyl)ethanone]. The synthesis of $\beta$-disubstituted ketones directly from two different secondary alcohols requires four elementary steps: dehydrogenation, aldol condensation, hydrogenation of an $\alpha, \beta$-unsaturated ketone, and oxidation of the resulting secondary alcohol functionality. Inspired by recent green catalytic transformations that emanated from our group, ${ }^{18}$ we have developed a direct synthesis of $\beta$ -

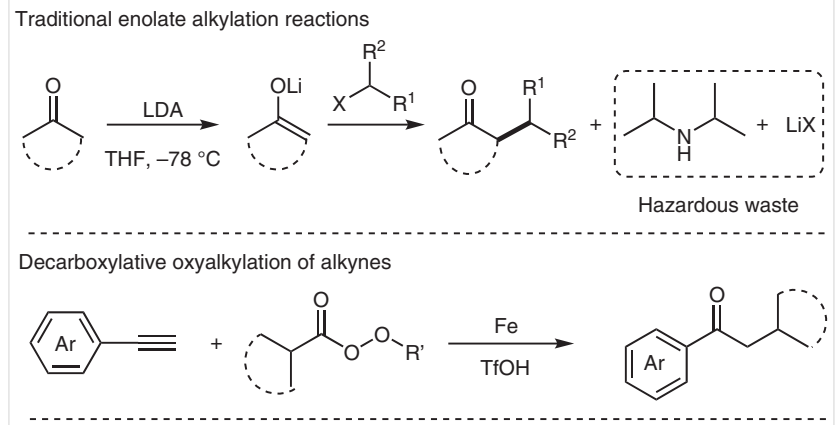

Decarboxylative alkylation of cinnamic acids

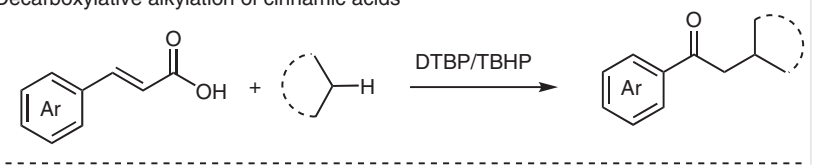

Grignard cross-coupling

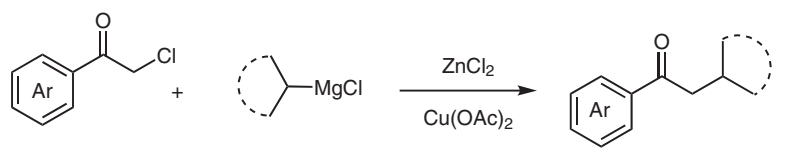

Oxo-alkylation of styrenes

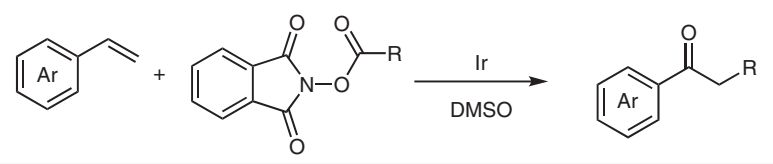

Scheme 4 Recent reports in synthesis of $\beta$-disubstituted ketones

disubstituted ketones from two different secondary alcohols. ${ }^{12}$ Notably, all the fundamental transformations occur in a single-step and the catalytic cross-coupling reaction does not require stoichiometric bases or oxidants; instead, it requires only a catalyst and a catalytic amount of base. Water and liberated $\mathrm{H}_{2}$ are the only byproducts.

\section{Scope of Ruthenium-Catalyzed Cross-Cou- pling of Secondary Alcohols}

To verify our hypothesis, we screened various reaction conditions for the ruthenium-catalyzed cross-coupling of secondary alcohols. Inspired by our recent studies, we chose Ru-MACHO 1 (1 mol\%) as the catalyst with 1-phenylethanol $(0.5 \mathrm{mmol})$ and cyclohexanol $(0.5 \mathrm{mmol})$ as reactants in the presence of $t$-BuOK $(2 \mathrm{~mol} \%)$ in toluene solution at $135^{\circ} \mathrm{C}$ as our model conditions; these provided the complete conversion of both alcohols, and the expected crosscoupled product was isolated in $69 \%$ yield (Table 1 , entry 1 ). Traces of the self-coupled product and unreacted acetophenone were also obtained. A high catalytic reactivity was observed when the base loading was increased to $5 \mathrm{~mol} \%$ and the temperature was reduced to $125^{\circ} \mathrm{C}$, which provided the product in $86 \%$ yield (entry 3 ). Further increases in the base loading, decreases in the catalyst loading, lower tempera- 
tures, or replacement of $t$-BuOK with $t$-BuONa resulted in considerably lower yields (entries 4-8). Control experiments with only the base and without the catalyst 1 or base confirmed that no product formation occurs without the catalyst (entries 9 and 10).

Table 1 Optimization of the Reaction Conditions ${ }^{\mathrm{a}}$

\begin{tabular}{llllll}
\hline Entry & Catalyst (mol\%) & Base (mol\%) & Temp $\left({ }^{\circ} \mathrm{C}\right)$ & Conv. $^{b}(\%)$ & Yield $^{c}(\%)$ \\
\hline 1 & 1 & 2 & 135 & $>99$ & $69(74)$ \\
2 & 1 & 5 & 135 & $>99$ & $85(90)$ \\
$\mathbf{3}$ & $\mathbf{1}$ & $\mathbf{5}$ & $\mathbf{1 2 5}$ & $>99$ & $\mathbf{8 6}(\mathbf{9 1})$ \\
4 & 1 & 10 & 125 & $>99$ & $70(76)$ \\
$5^{\mathrm{d}}$ & 1 & 5 & 125 & $>99$ & $87(94)$ \\
6 & 1 & 5 & 115 & 94 & $63(69)$ \\
7 & 0.5 & 5 & 125 & $>99$ & $70(72)$ \\
$8^{\text {e }}$ & 1 & 5 & 125 & $>99$ & $79(83)$ \\
$9^{f}$ & - & 5 & 125 & 5 & - \\
$10^{f}$ & - & - & 125 & - & - \\
\hline
\end{tabular}

${ }^{a}$ Reaction conditions: 1-phenylethanol $(0.5 \mathrm{mmol})$, cyclohexanol $(0.5$ mmol), toluene $(1.5 \mathrm{ml})$, catalyst $1(1 \mathrm{~mol} \%), t$-BuOK $(5 \mathrm{~mol} \%), 125^{\circ} \mathrm{C}$, under flowing argon.

${ }^{b}$ Conversion of 1-phenylethanol as determined by GC analysis with benzene as internal standard.

' Yields of isolated products after column chromatography; yields calculated by GC analysis of the reaction mixtures are given in parentheses.

d Cyclohexanol (2 equiv) was used.

e $5 \mathrm{~mol} \%$ of $t$-BuONa was used.

${ }^{\mathrm{f}}$ The reaction was performed for $24 \mathrm{~h}$.

With the optimized reaction condition in hand, we examined the scope of the secondary alcohols in cross-coupling with cyclohexanol (Scheme 5). 1-Phenylethanols containing electron-donating substitution on the aryl ring afforded the corresponding cross-coupled products $\mathbf{2 a - i}$ in yields of $60-90 \%$ (Scheme 5). Interestingly, aryl secondary alcohols having electron-withdrawing groups were well tolerated: the reaction of 1-(4-chlorophenyl)ethanol with cyclohexanol provided product $\mathbf{2 j}$ in $48 \%$ yield. Heterocyclic secondary alcohols reacted with cyclohexanol to give the cross-coupled products $\mathbf{2 k}$ and $\mathbf{2 1}$ in good yields. Bicyclic aromatic secondary alcohols gave products $\mathbf{2 m - \mathbf { o }}$ in very good yields.

We next investigated whether the same strategy could be applied to other cyclic or acyclic secondary alcohols. Surprisingly, both cyclic and acyclic secondary alcohols directly coupled with benzylic secondary alcohols to give good to excellent yields of the cross-coupled ketone products (Scheme 6). Under the optimized reaction conditions, substituted cyclohexanols gave the corresponding crosscoupled products as mixtures of diastereomers whose diastereomeric ratios were determined by ${ }^{1} \mathrm{H}$ NMR analysis of the crude reaction mixtures. The reaction of various 1-arylethanol derivatives with 4-methylcyclohexanol gave the cross-coupled ketone products $3 \mathbf{a}-\mathbf{c}(\mathrm{dr}=80: 20,81: 19$, and $78: 22$, respectively) in good yields as mixture of diastereomers. Similar diastereoselectivities were observed for 4propyl-, 4-tert-butyl-, and 4-phenylcyclohexanol, which gave products 3d-g in good yields. 1-Cycloheptanol and 2norborneol reacted with 1-phenylethanol derivatives to give the corresponding ketone products $\mathbf{3 h}-\mathbf{k}$ in good yields (Scheme 6). 1,4-Dioxaspiro[4.5]decan-8-ol and diphenylmethanol reacted with 1-arylethanol derivatives to give products $\mathbf{3 l}$ and $\mathbf{3 m}$ in moderate yields. Next, highly challenging and nonactivated linear-chain aliphatic secondary alcohols were employed in this selective cross-coupling of secondary alcohols in the presence of an increased catalyst loading of 1 ( $4 \mathrm{~mol} \%$ ) and of base (20 mol\%). Ultimately, a variety of secondary alcohols such as propan-2-ol, butan-2ol, pentan-2-ol, pentan-3-ol, and heptan-4-ol were well tolerated and were selectively converted into the corresponding $\beta$-disubstituted ketones $\mathbf{3 n}$-t $\mathbf{t}$ in good to excellent yields.

\section{Mechanistic Studies and Proposed Mecha- nism}

To gain mechanistic insights, the cross-coupling of 1phenylethanol with cyclohexanol was monitored under the optimized reaction conditions. GC analysis of the reaction mixture at regular intervals indicated that the reaction follows first-order kinetics with respect to the consumption of 1-phenylethanol. Interestingly, when 1-mesitylethanol reacted with sterically hindered adamantan-2-ol, the olefin product $\mathbf{5 a}$ formed selectively and was isolated in $87 \%$ yield (Scheme 7a). Analysis of the crude reaction mixture by GC clearly indicated the absence of alkylated product. Moreover, the reaction of 1-mesitylethanol with heptan-4-ol under the optimized conditions provided alkylated product $\mathbf{3 t}$ and olefin product $\mathbf{5 b}$ in a 90:10 ratio (Scheme $7 b$ ). These results indicate that the borrowing-hydrogen pathway was interrupted due to steric encumbrance of the ruthenium on catalyst 1 and that the reaction proceeded via $\alpha, \beta$-unsaturated ketone intermediates. In addition, deuterium-labeling experiments conducted by using deuterated alcohols suggested that the liberated dideutrium/dihydrogen from cyclohexanol was predominantly reinstalled on an $\alpha, \beta$-unsaturated intermediate formed in situ, rather than 1-phenylethanol (Schemes 7c and 7d).

On the basis of our previous reports ${ }^{18}$ and experimental evidence, a catalytic cycle for the cross-coupling of secondary alcohols catalyzed by the Ru-MACHO catalyst $\mathbf{1}$ is proposed (Scheme 8). Previously, facile $\mathrm{O}-\mathrm{H}, \mathrm{O}-\mathrm{D}, \mathrm{N}-\mathrm{H}$, and $\mathrm{C}(\mathrm{sp})-\mathrm{H}$ bond-activation reactions by catalyst $\mathbf{1}$ have been established. ${ }^{12,18}$ Catalyst 1 reacts with base to generate a coordinatively unsaturated reactive intermediate I, previously observed in mass spectrometric analyses. ${ }^{18 \mathrm{~d}, 19}$ The reactive 


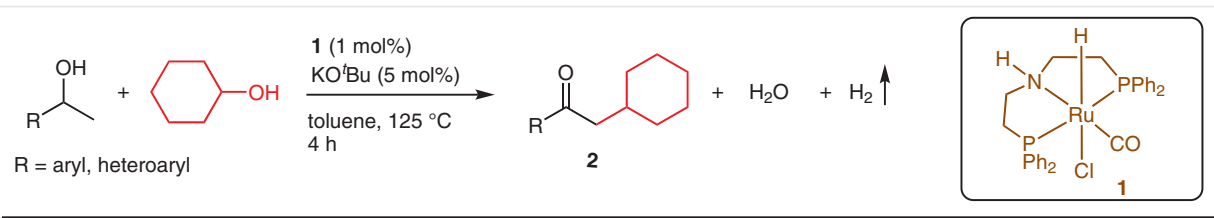

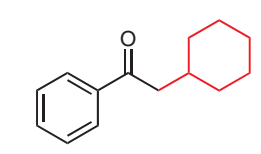

2a, $86 \%$ (>99\%)<smiles>Cc1ccccc1C(=O)CC1CCCCC1</smiles>

2b, $90 \%$ (>99\%)<smiles>Cc1ccc(C(=O)CC2CCCCC2)cc1</smiles>

2c, $85 \%(>99 \%)$<smiles>COc1ccccc1C(=O)CC1CCCCC1</smiles>

2d, $67 \%(75 \%)$<smiles>COc1ccc(C(=O)CC2CCCCC2)cc1</smiles><smiles>Cc1cc(C)c(C(=O)CC2CCCCC2)c(C)c1</smiles><smiles>COc1cc(C(=O)CC2CCCCC2)cc(OC)c1OC</smiles>

2g, $63 \%$ (>99\%)<smiles>COc1cc(OC)c(C(=O)CC2CCCCC2)c(OC)c1</smiles>

2h, 78\% (>99\%)<smiles>O=C(CC1CCCCC1)c1ccc(OCc2ccccc2)cc1</smiles>

2i, $78 \%(91 \%)$<smiles>O=C(CC1CCCCC1)c1ccc(Cl)cc1</smiles><smiles>O=C(CC1CCCCC1)c1cccnc1</smiles><smiles>O=C(CC1CCCCC1)c1cnc2ccccc2c1</smiles>

2j, $48 \%$ (60\%)

2k, $72 \%$ (99\%) 2I, $82 \%$ (>99\%)<smiles>O=C(CC1CCCCC1)c1ccc2c(c1)CCCC2</smiles>

2m, 87\% (>99\%)

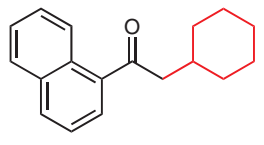

2n, $83 \%$ (>99\%)<smiles>O=C(CC1CCCCC1)c1ccc2ccccc2c1</smiles>

2o, $86 \%(97 \%)$

Scheme 5 Scope of ruthenium-catalyzed cross-coupling of secondary alcohols with cyclohexanol

intermediate I reacts with both the secondary alcohols to provide the alkoxy-ligand-coordinated ruthenium intermediates II and II' upon $\mathrm{O}-\mathrm{H}$ activation, as previously established by us. ${ }^{18 f}$ The amide donor present in the unsaturated intermediate $\mathbf{I}$ accepts a proton upon activation of the $\mathrm{O}-\mathrm{H}$ bond and become the amine donor in intermediates II and II'. In concert with the metal center, the ligand motif participates in bond formation and bond breaking, and hence displays metal-ligand cooperation. Further, $\beta$-hydride elimination from intermediates II and II' might result in the formation of ketone intermediates $\mathbf{A}$ and $\mathbf{B}$, and both dehydrogenation reactions converge to provide the same ruthenium dihydride complex III. Although there is no evidence for it, the involvement of other mechanistic pathways cannot be ruled out. ${ }^{20}$ Furthermore, in the presence of base, a cross-aldol condensation reaction between ketones $\mathbf{A}$ and $\mathbf{B}$, formed in situ, generates the $\alpha, \beta$-unsaturated carbonyl compound $\mathbf{C}$. Further, selective hydrogenation by complex III provided the desired $\beta$-disubstituted ketone. The amine-amide metal-ligand cooperation that is operative in these catalytic intermediates allows the regeneration of catalytic active intermediate I upon hydrogenation, as well as the liberation of a $\mathrm{H}_{2}$ molecule from the ruthenium dihydride III.

\section{Conclusion}

We have demonstrated an unprecedented rutheniumcatalyzed selective and highly efficient cross-coupling of secondary alcohols to provide $\beta$-disubstituted ketones. The catalytic system exhibits a high activity and selectivity with a broad substrate scope. The reaction proceeded through acceptorless dehydrogenation of secondary alcohols to provide the corresponding ketones. Furthermore, under basic conditions, an aldol condensation followed by selective hydrogenation of an $\alpha, \beta$-unsaturated ketone intermediate, formed in situ, provides $\beta$-disubstituted ketones.

Detailed kinetic and deuterium-labeling studies suggested that aliphatic secondary alcohols oxidize faster than do benzylic secondary alcohols, which facilitates the selective formation of cross-coupling products. Notably, hydrogen and water are the only byproducts liberated by this 


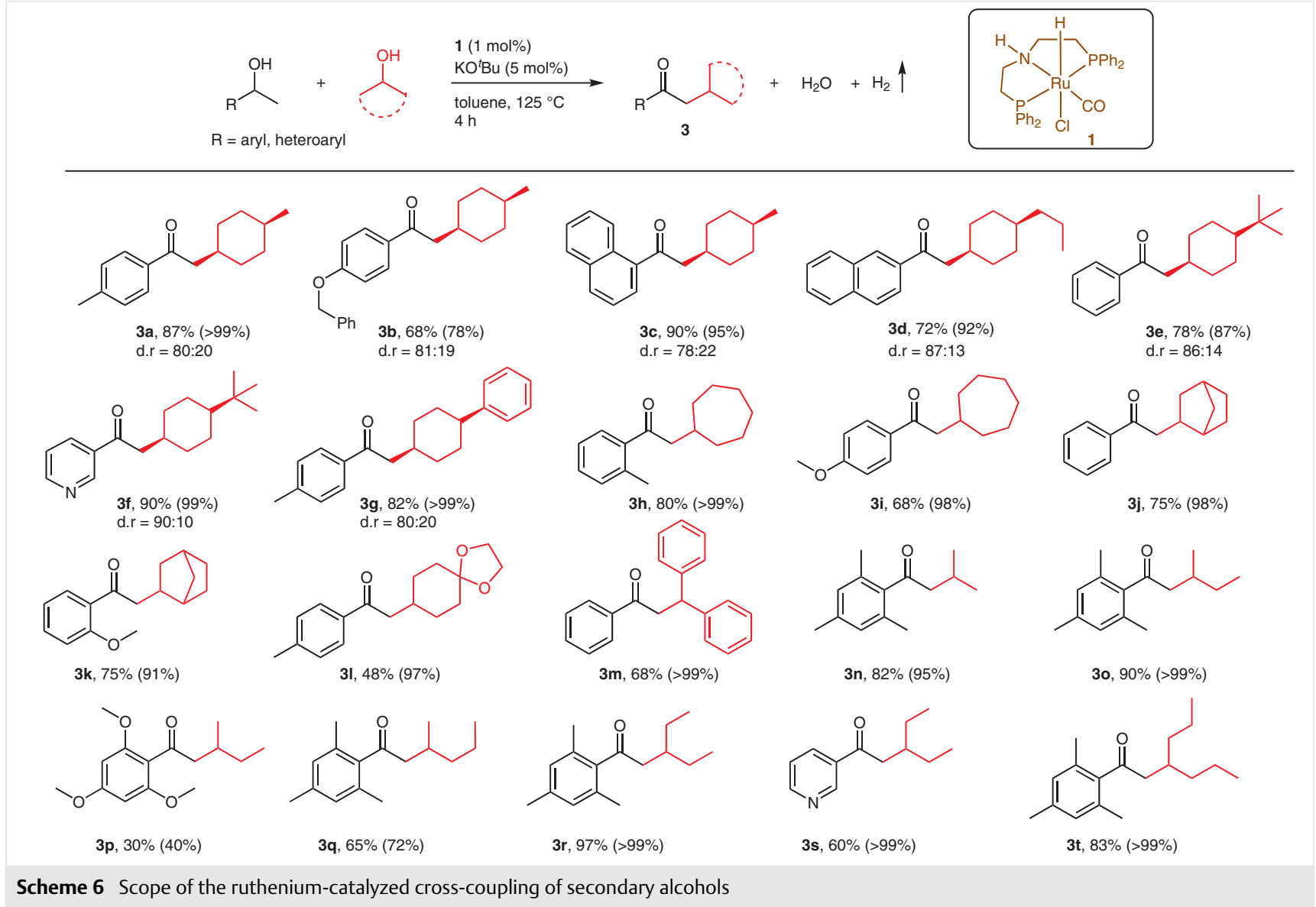

a)<smiles>Cc1cc(C)c(C(C)O)c(C)c1</smiles>

5 a, $87 \%(94 \%)$<smiles>CCCC(O)CCCC(CC(=O)c1c(C)cc(C)cc1C)C(=O)CC(CCC)CCC</smiles>

c)<smiles>CC1(C(O)C(=O)c2ccccc2)CCCCC1</smiles>

$\alpha$ and $\beta=93 \%$

yield $=76 \%$

d)

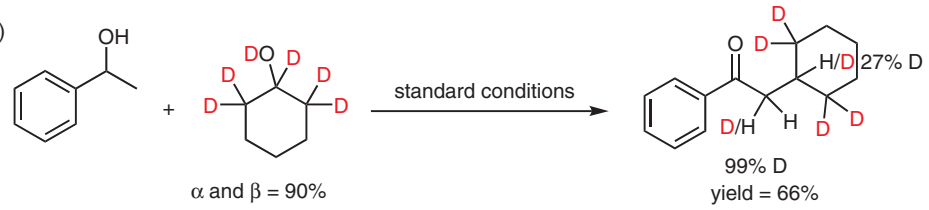

Scheme 7 Mechanistic investigations. (Reprinted with permission from reference 12. @ 2019, American Chemical Society.) 


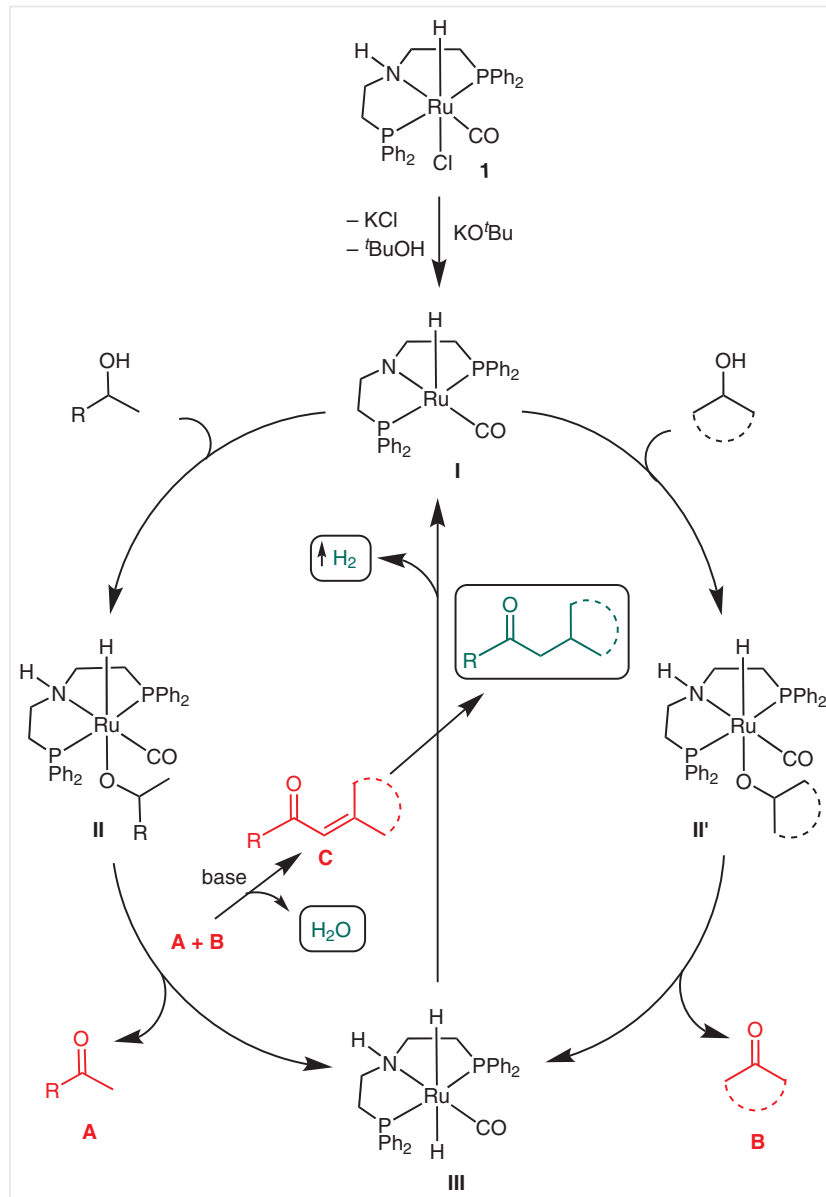

Scheme 8 Proposed catalytic cycle for the cross-coupling of secondary alcohols. (Reprinted with permission from reference 12. @ 2019, American Chemical Society.)

green catalytic protocol. This new cross-coupling reaction protocol will be an important development in the synthesis of $\beta$-disubstituted ketones, and should be applicable to laboratory and industrial-scale chemical syntheses.

\section{Funding Information}

We thank SERB New Delhi (EMR/2016/002517), DAE, and NISER for financial support.

\section{Acknowledgment}

S.T. thanks UGC for a research fellowship. We thank Professor J. V. Yeldho for his kind help.

\section{References}

(1) (a) Toh, Q. Y.; McNally, A.; Vera, S.; Erdmann, N.; Gaunt, M. J. J. Am. Chem. Soc. 2013, 135, 3772. (b) Maeyama, K.; Yamashita, K.; Saito, H.; Aikawa, S.; Yoshida, Y. Polym. J. (Tokyo) 2012, 44, 315. (c) Vooturi, S. K.; Cheung, C. M.; Rybak, M. J.; Firestine, S.
M.J. Med. Chem. 2009, 52, 5020. (d) Walter, M. W. Nat. Prod. Rep. 2002, 19, 278. (e) Smith, M. B.; March, J. March's Advanced Organic Chemistry: Reactions, Mechanisms, and Structure, 6th ed; Wiley-Interscience: Hoboken, 2007.

(2) (a) Caine, D. In Comprehensive Organic Synthesis, Vol. 3; Trost, B. M.; Fleming, I., Ed.; Pergamon: Oxford, 1991, Chap. 1.1, 1-63. (b) Reetz, M. T. Angew. Chem., Int. Ed. Engl. 1982, 21, 96.

(3) (a) Parthasarathy, G.; Hart, R.; Jamro, E.; Miner, L. Clean Technol. Environ. Policy 2005, 7, 219. (b) Metzger, J. O.; Eissen, M. C. $R$. Chim. 2004, 7, 569. (c) Jenck, J. F.; Agterberg, F.; Droescher, M. J. Green Chem. 2004, 6, 544.

(4) (a) Huang, F.; Liu, Z.; Yu, Z. Angew. Chem. Int. Ed. 2016, 55, 862. (b) Obora, Y. Top. Curr. Chem. 2016, 374, 1. (c) Obora, Y. ACS Catal. 2014, 4, 3972.

(5) For reviews on borrowing-hydrogen methodology, see: (a) Corma, A.; Navas, J.; Sabater, M. J. Chem. Rev. 2018, 118, 1410. (b) Faisca Phillips, A. M.; Pombeiro, A. J. L.; Kopylovich, M. N. ChemCatChem 2017, 9, 217. (c) Chelucci, G. Coord. Chem. Rev. 2017, 331, 1. (d) Yang, Q.; Wang, Q.; Yu, Z. Chem. Soc. Rev. 2015, 44, 2305. (e) Nandakumar, A.; Midya, S. P.; Landge, V. G.; Balaraman, E. Angew. Chem. Int. Ed. 2015, 54, 11022. (f) Ketcham, J. M.; Shin, I.; Montgomery, T. P.; Kriche, M. J. Angew. Chem. Int. Ed. 2014, 53, 9142. (g) Pan, S.; Shibata, T. ACS Catal. 2013, 3, 704. (h) Obora, T. D.; Ishii, Y. Synlett 2011, 2011, 30. (i) Bähn, S.; Imm, S.; Neubert, L.; Zhang, M.; Neumann, H.; Beller, M. ChemCatChem 2011, 3, 1853. (j) Dobereiner, G. E.; Crabtree, R. H. Chem. Rev. 2010, 110, 681. (k) Guillena, G.; Ramón, D. J.; Yus, M. Chem. Rev. 2010, 110, 1611. (l) Watson, A. J. A.; Williams, J. M. J. Science 2010, 329, 635. (m) Nixon, T. D.; Whittlesey, M. K.; Williams, J. M. J. Dalton Trans. 2009, 753. (n) Hamid, M. H. S. A.; Slatford, P. A.; Williams, J. M. J. Adv. Synth. Catal. 2007, 349, 1555. (o) Guillena, G.; Ramón, D. J.; Yus, M. Angew. Chem. Int. Ed. 2007, 46, 2358.

(6) For reviews on acceptorless dehydrogenation of alcohols, see: (a) Crabtree, R. H. Chem. Rev. 2017, 117, 9228. (b) Khusnutdinova, J. R.; Milstein, D. Angew. Chem. Int. Ed. 2015, 54, 12236. (c) Gunanathan, C.; Milstein, D. Chem. Rev. 2014, 114, 12024. (d) Gunanathan, C.; Milstein, D. Science 2013, 341, 1229712. (e) Gunanathan, C.; Milstein, D. Acc. Chem. Res. 2011, $44,588$.

(7) (a) Das, U. K.; Ben-David, Y.; Leitus, G.; Diskin-Posner, Y.; Milstein, D. ACS Catal. 2019, 9, 479. (b) Paudel, K.; Pandey, B.; Xu, S.; Taylor, D. K.; Tyer, D. L.; Torres, C. L.; Gallagher, S.; Kong, L.; Ding, K. Org. Lett. 2018, 20, 4478. (c) Nielsen, M.; Junge, H.; Kammer, A.; Beller, M. Angew. Chem. Int. Ed. 2012, 51, 5711. (d) Sølvhøj, A.; Madsen, R. Organometallics 2011, 30, 6044. (e) Gnanaprakasam, B.; Ben-David, Y.; Milstein, D. Adv. Synth. Catal. 2010, 352, 3169. (f) Gunanathan, C.; Shimon, L. J. W.; Milstein, D. J. Am. Chem. Soc. 2009, 131, 3146. (g) Zhang, J.; Leitus, G.; Ben-David, Y.; Milstein, D. J. Am. Chem. Soc. 2005, 127, 10840.

(8) (a) Chakraborty, S.; Daw, P.; Ben-David, Y.; Milstein, D. ACS Catal. 2018, 8, 10300. (b) Tan, D.-W.; Li, H.-X.; Zhu, D.-L.; Li, H.Y.; Young, D. J.; Yao, J.-L.; Lang, J.-P. Org. Lett. 2018, 20, 608. (c) Sahoo, A. R.; Lalitha, G.; Murugesh, V.; Bruneau, C.; Sharma, G. V. M.; Suresh, S.; Achard, M. J. Org. Chem. 2017, 82, 10727. (d) Jiménez, M. V.; Fernández-Tornos, J.; Modrego, F. J.; PérezTorrente, J. J.; Oro, L. A. Chem. Eur. J. 2015, 21, 17877.

(9) (a) Aitchison, H.; Wingad, R. L.; Wass, D. F. ACS Catal. 2016, 6, 7125. (b) Xie, Y.; Ben-David, Y.; Shimon, L. J. W.; Milstein, D. J. Am. Chem. Soc. 2016, 138, 9077. (c) Kozlowski, J. T.; Davis, R. J. ACS Catal. 2013, 3, 1588 . 
(10) (a) Chaudhari, C.; Siddiki, S. M. A. H.; Shimizu, K.-i. Top. Catal. 2014, 57, 1042. (b) Makarov, I. S.; Madsen, R. J. Org. Chem. 2013, $78,6593$.

(11) (a) Liu, T.; Wang, L.; Wu, K.; Yu, Z. ACS Catal. 2018, 8, 7201. (b) Roy, B. C.; Debnath, S.; Chakrabarti, K.; Paul, B.; Maji, M.; Kundu, S. Org. Chem. Front. 2018, 5, 1008. (c) Shee, S.; Paul, B.; Panja, D.; Roy, B. C.; Chakrabarti, K.; Ganguli, K.; Das, A.; Das, G. K.; Kundu, S. Adv. Synth. Catal. 2017, 359, 3888. (d) Wang, Q.; Wu, K.; Yu, Z. Organometallics 2016, 35, 1251.

(12) Thiyagarajan, S.; Gunanathan, C. J. Am. Chem. Soc. 2019, 141, 3822.

(13) Ji, J.; Liu, P.; Sun, P. Chem. Commun. 2015, 51, 7546.

(14) Zhu, X.; Ye, C.; Li, Y.; Bao, H. Chem. Eur. J. 2017, 23, 10254.

(15) Rey, J.; Hu, H.; Snyder, J. P.; Barrett, A. G. M. Tetrahedron 2012, 68, 9211.

(16) (a) Kong, W.; Yu, C.; An, H.; Song, Q. Org. Lett. 2018, 20, 349. (b) Xia, Z.-H.; Zhang, C.-L.; Gao, Z.-H.; Ye, S. Org. Lett. 2018, 20, 3496.
(17) Akhtar, W. M.; Cheong, C. B.; Frost, J. R.; Christensen, K. E.; Stevenson, N. G.; Donohoe, T. J. J. Am. Chem. Soc. 2017, 139, 2577.

(18) (a) Thiyagarajan, S.; Gunanathan, C. ACS Catal. 2018, 8, 2473. (b) Krishnakumar, V.; Gunanathan, C. Chem. Commun. 2018, 54 , 8705. (c) Thiyagarajan, S.; Gunanathan, C. ACS Catal. 2017, 7, 5483. (d) Krishnakumar, V.; Chatterjee, B.; Gunanathan, C. Inorg. Chem. 2017, 56, 7278. (e) Chatterjee, B.; Gunanathan, C. Chem. Commun. 2016, 52, 4509. (f) Chatterjee, B.; Gunanathan, C. Org. Lett. 2015, 17, 4794.

(19) Anaby, A.; Schelwies, M.; Schwaben, J.; Rominger, F.; Hashmi, A. S. K.; Schaub, T. Organometallics 2018, 37, 2193.

(20) Chakraborty, S.; Lagaditis, P. O.; Förster, M.; Bielinski, E. A.; Hazari, N.; Holthausen, M. C.; Jones, W. D.; Schneider, S. ACS Catal. 2014, 4, 3994. 